\title{
REVIEWS
}

\section{Meningococcal genome dynamics}

\section{Tonje Davidsen and Tone Tønjum}

\begin{abstract}
Neisseria meningitidis (the meningococcus) is an important commensal, pathogen and model organism that faces up to the environment in its exclusive human host with a small but hyperdynamic genome. Compared with Escherichia coli, several DNA-repair genes are absent in N. meningitidis, whereas the gene products of others interact differently. Instead of responding to external stimuli, the meningococcus spontaneously produces a plethora of genetic variants. The frequent genomic alterations and polymorphisms have profound consequences for the interaction of this microorganism with its host, impacting structural and antigenic changes in crucial surface components that are relevant for adherence and invasion as well as antibiotic resistance and vaccine development.
\end{abstract}

\section{Meningitis \\ Inflammation of the \\ membranes (meninges) \\ surrounding the brain.}

Salpingitis

Inflammation of the fallopian tubes.

Recombination

The process by which parts, or all, of DNA molecules from two separate sources are

exchanged or brought together into a single unit.

\section{Oxidative burst}

The release of reactive oxygen species by specialized immune cells of humans.

DNA uptake sequences (DUS). Small repeated sequences that are required for DNA binding or uptake in natural transformation in members of the genus Neisseria.

Centre for Molecular Biology and Neuroscience and Institute of Microbiology. University of Oslo,

Rikshospitalet, N-0027 Oslo, Norway.

Correspondence to T.T.

e-mail:

tone.tonjum@medisin.uio.no

doi:10.1038/nrmicro1324
Infections caused by Neisseria meningitidis (the meningococcus) are associated with significant morbidity and mortality worldwide. This Gram-negative diplococcus usually colonizes the human oral mucosa without causing disease. The organism is carried by $\sim 20 \%$ of the human population, with increased carriage rates in crowded settings such as childcare facilities and military camps. For reasons that are largely unknown, the meningococcus can invade the pharyngeal mucosal epithelium and, in the absence of bactericidal serum activity, disseminate into the bloodstream, causing septicaemia. N. meningitidis can also cross the blood-brain barrier and infect the cerebrospinal fluid, causing meningitis. Systemic meningococcal disease primarily affects young children and adolescents, often leading to neurological sequelae or having a fatal outcome. Apart from epidemic outbreaks, approximately 500,000 cases of meningococcal disease are estimated to occur yearly on a worldwide basis ${ }^{1}$. The ability of the meningococcus to inflict damage in its exclusive human host is correlated with adherence to mucosal epithelial cells in the nasopharynx, and the ability to invade subepithelial tissues and blood vessels on its way through the blood-brain barrier to the cerebrospinal fluid ${ }^{2,3}$. By contrast, the closely related Neisseria gonorrhoeae (the gonococcus) is transmitted sexually, infects the mucosa of the urogenital tract, can cause salpingitis and pelvic inflammatory disease in women, but rarely proceeds to systemic infection ${ }^{4}$.

In the meningococcal cell, as in any living cell, metabolic activity produces reactive oxygen species that can damage DNA, and the spontaneous decay of the DNA structure, for example, manifested by the hydrolytic loss or deamination of bases, causes DNA-damage events ${ }^{5}$. Also, horizontal gene transfer and frequent recombination events challenge meningococcal genomic stability. Furthermore, in its local environment in the oral mucosal surface (during its commensal phase) or the bloodstream and meninges (during disease), the meningococcal genome experiences attacks from harmful agents generated from the human host, for instance through the oxidative burst. To adapt and avoid the host immune defences, the meningococcus must possess mechanisms for rapid genome variation and diversification. To accommodate the meningococcus in the changing environments and selective pressures in its habitat, there is a concomitant need for genome variation and genome maintenance - a potentially conflicting scenario. DNA-repair mechanisms are therefore likely to have a key role in meningococcal genome dynamics.

Each microbial species has its own profile of genes for DNA repair and recombination ${ }^{6}$, and this profile is important for microbial fitness, survival and virulence, as well as strain diversification and development of drug resistance ${ }^{7}$ (FIG. 1). In this review, we consider the meningococcal DNA-repair profile, as contrasted with that of Escherichia coli. We discuss mechanisms of meningococcal genome instability that contribute to high genome fluidity, elucidating the consequent need for DNA repair. Much experimental data on neisserial DNA repair stems from the gonococcus. However, as the gonococcus shares extensive genomic identity ( 96\%) with the meningococcus, relevant experiments conducted in the gonococcus will be used to illustrate certain points concerning meninogoccal DNA repair. Finally, we consider the impact of sequence repeats, and in particular the DNA uptake sequences (DUSs) required for transformation, on meningococcal genome dynamics. 


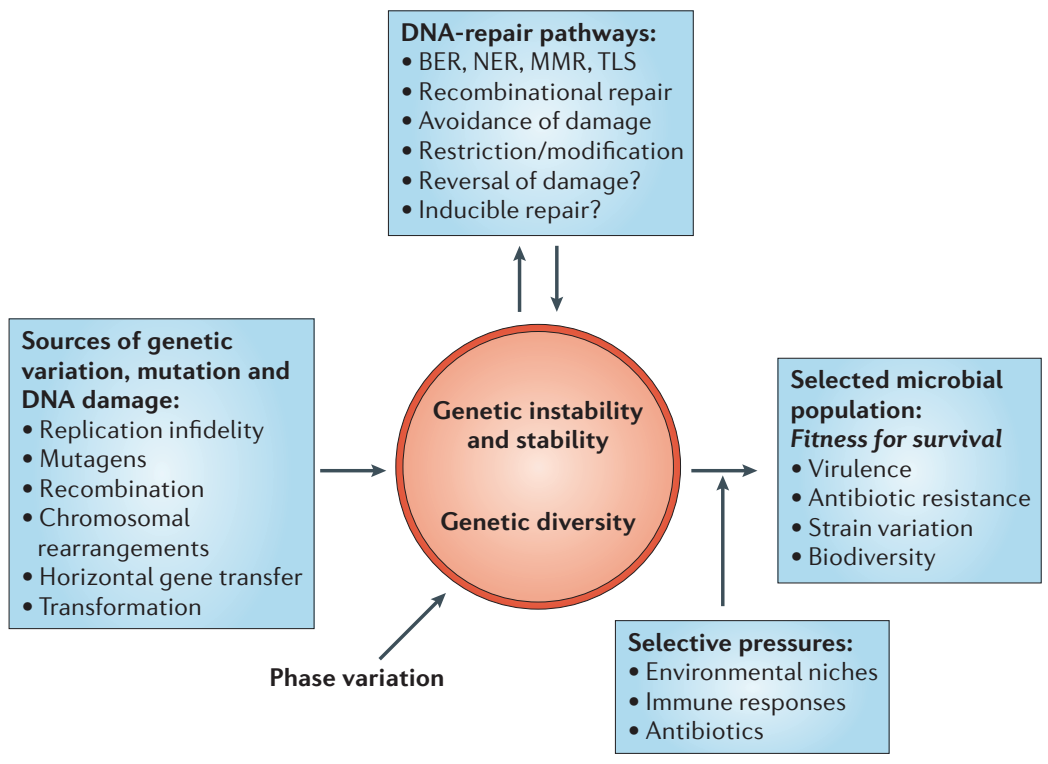

Figure 1 | Genetic diversity, genetic instability and fitness of the meningococcus. The balance between sources of genetic variation, DNA repair and selective pressures defines the genetic diversity and fitness of the meningococcal population. Endogenous and exogenous stresses lead to mutations and DNA damage that will often be harmful, but simultaneously represent a source of genomic variation. Horizontal gene transfer and recombination direct genomic diversification by incorporating new genetic information and shuffling the genome. Phase variation and antigenic variation produce diverse antigens in important surface-associated virulence factors, and constitute an important pathway for the avoidance of host immune systems. The meningococcus therefore relies on frequent genetic diversification to produce a surplus of spontaneous variants. Although genomic variation is a prerequisite for meningococcal fitness and survival, the result of an 'everchanging' genome is genomic instability. To balance the sources of genetic variation, the meningococcus has DNA-repair pathways; however, the contribution of each of these to the balancing act awaits further examination. Selective pressures in the meningococcus habitat, such as environmental characteristics, immune responses and antibiotics, influence meningococcal fitness for survival. Among the surviving meningococcal cells, certain variants will be optimally fit, and these might have selected properties such as increased virulence and antibiotic resistance. BER, base excision repair; MMR, mismatch repair; NER, nucleotide excision repair; TLS, translesion synthesis. Modified with permission from REF. 7 (C) (2001) Elsevier.

Excision repair

A process for repairing altered bases, mismatches or small loops in DNA, in which a singlestranded section containing the aberrant structure is removed and the resulting gap is filled by DNA replication that is templated from the complementary strand.

Base excision repair (BER). The excision and repair of bases that have been altered by small chemical

modifications

Mismatch repair (MMR). An excision-repair pathway that identifies and corrects mispaired bases and 1-3-nucleotide loops.

\section{The meningococcal DNA-repair profile}

Reactive metabolites formed during normal cell function (endogenous processes), as well as environmental stimuli (exogenous stress), cause DNA damage ${ }^{5}$. The repair machinery that protects against these DNA lesions has been extensively studied in both prokaryotes and eukaryotes ${ }^{6,8}$, and the pathways that operate in E. coli have served as a model for DNArepair systems in other microorganisms. According to the E. coli paradigm, excision repair pathways include base excision repair (BER), mismatch repair (MMR) and nucleotide excision repair (NER), whereas other repair strategies encompass recombinational repair, reversal of DNA damage and tolerance of DNA damage (FIG. 2). A comparison of the three completed meningococcal genome sequences ${ }^{9,10}$ and one gonococcal genome sequence (see Online links box) with $E$. coli has disclosed interesting findings concerning the occurrence of DNA-repair genes in the neisseriae (TABLE 1).
Base excision repair. Aerobic organisms are prone to oxidative DNA damage, as reactive oxygen species are formed during normal metabolism. Furthermore, the meningococcus is exposed to high loads of external oxygen sources in its habitat in the human airways, and through host defence systems such as the oxidative burst. The defence against oxidative DNA damage might therefore be particularly important in this organism. One of the most frequent forms of oxidative DNA damage is the oxidation product of guanine, 7,8-dihydro-8-oxo$2^{\prime}$-deoxyguanosine $(80 x 0 G)^{11}$, which can result in base mispairing during DNA replication. The BER pathway is probably the cell's most important line of defence against the deleterious effects of such DNA damage ${ }^{12}$. BER involves the release of modified base residues from DNA by DNA glycosylases that leave abasic (AP) sites in the DNA (FIG. 2). The AP site is cleaved by the AP-lyase activity of DNA glycosylases or by an AP endonuclease, leaving a strand break, which is repaired by enzymes that include a phosphodiesterase that removes the remaining deoxyribose phosphate residue, a DNA polymerase and a DNA ligase.

The meningococcal genome sequences reveal that homologues of all components of the BER pathway are present, although homologues of the DNA glycosylases $n e i$ and alkA and the endonuclease $n f o$ are missing (TABLE 1). The only meningococcal DNA-repair component fully characterized so far is the DNA glycosylase MutY, which participates in $\mathrm{BER}^{13}$. MutY is an atypical glycosylase - it removes adenine from DNA when it is mispaired with $80 x o G$, thereby preventing GC to TA transversions ${ }^{14}$. In E. coli, MutY acts together with the formamidopyrimidine DNA glycosylase (Fpg/MutM) and the hydrolase MutT, comprising the 80xoG system (GO system), to prevent fixation of mutations caused by $80 x 0 \mathrm{G}^{15}$. Inactivation of each of the individual GO genes in E. coli confers a mutator phenotype, and E. coli $f p g$, mut $Y$ and mutT mutants have been reported as weak, moderate and strong mutators, respectively ${ }^{15,16}$. By contrast, meningococcal $f p g$ mutants displayed only slight increases in mutagenicity, whereas neisserial mut $Y$ mutants have high spontaneous-mutation rates ${ }^{13}$ (FIG. 3). Furthermore, a mut $Y$ fpg double mutant revealed a striking increase in mutation rate (T.D. and T.T., unpublished results), indicating that, in the meningococcus, mut $Y$ and $f p g$ gene products act in synergy. This confirms a prominent role for MutY in neisserial DNA repair.

Mismatch repair. The MMR system recognizes base-base mismatches and insertion/deletion nucleotide loops that result from DNA-polymerase errors during replication ${ }^{17,18}$. In E. coli MMR, MutS mismatch recognition ${ }^{19,20}$ is followed by MutL recruitment ${ }^{21}$. Together, these enzymes activate $\mathrm{MutH}$, an endonuclease that directs strand specificity of the repair machinery (FIG. 2). The meningococcus has homologues of the genes that encode MMR enzymes MutS and MutL but lacks the MutH endonuclease, as do humans. It is possible that another meningococcal component carries out the MutH strand-specificity function found in E. coli, or that the meningococcus does not need this function. Stojiljkovic and co-workers hypothesized 


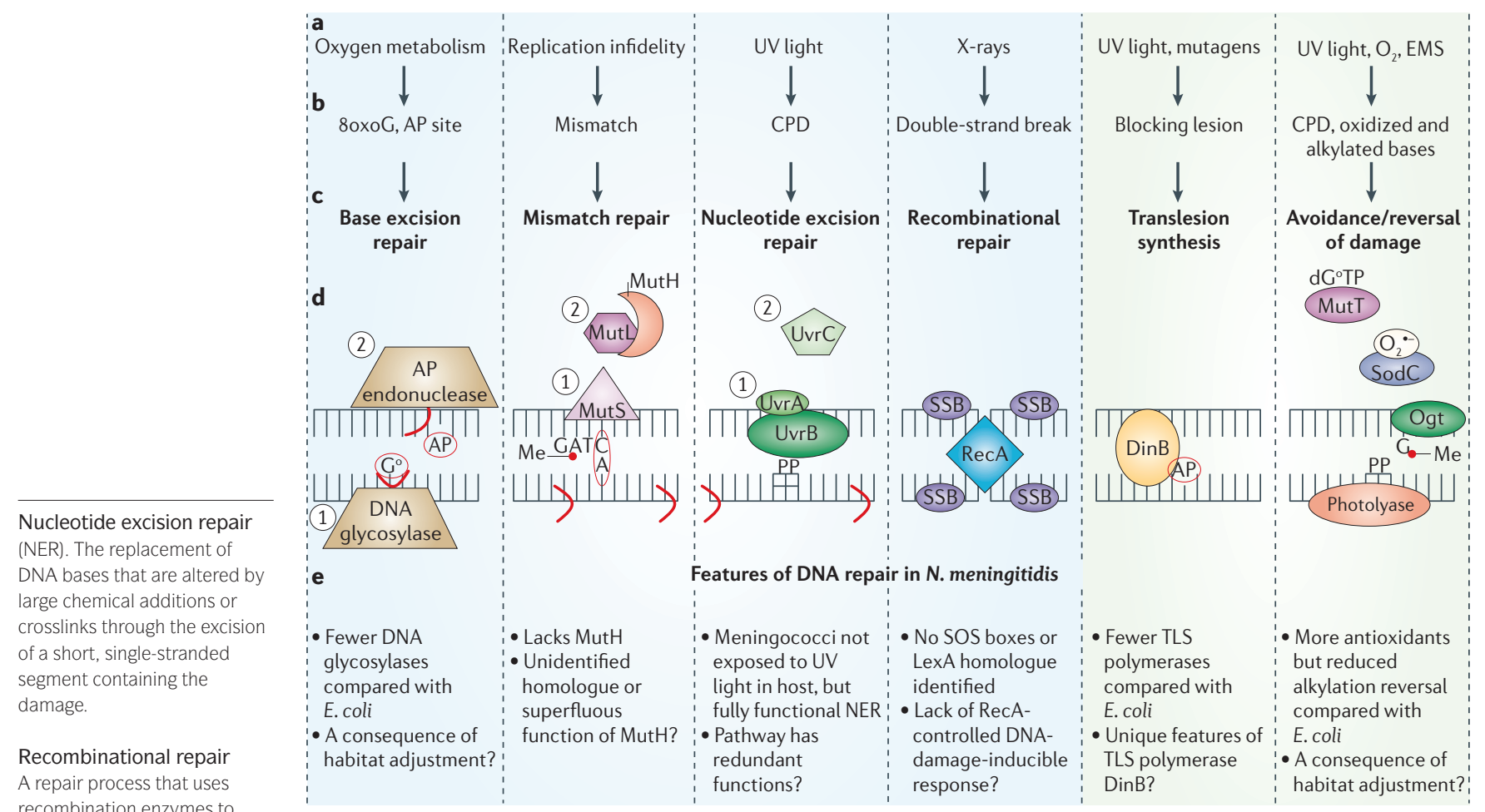
remove a DNA lesion and repair the patch by strand exchange.

\section{DNA glycosylase} An enzyme involved in base excision repair that hydrolyses the $N$-glycosylic bond to release the altered base from the sugar-phosphate backbone, leaving an abasic site.

\section{8oxoG system}

A DNA-repair system dedicated to the removal of the oxidized form of guanine, 8oxoG. Composed of a triplet of enzymes - MutY, MutM (Fpg) and MutT.

Mutator

A bacterial strain showing an elevated mutation rate.

Phase variation

A molecular mechanism leading to a switching of the gene expression state, for example, on-off expression. Mediated by tandem repeats within the promoter region or the open reading frame.

\section{SOS response}

An inducible response allowing bacteria to circumvent the presence of abundant DNA damage by activating several DNA-repair genes as well as translesion DNA polymerases that are under the control of the LexA protein.

Figure 2 | Major DNA-repair pathways in Escherichia coli and the meningococcus. Several pathways repair the cytotoxic and mutagenic effects of DNA damage that can arise through endogenous and exogenous stress. Mutagenic agents or processes (a) result in different types of DNA damage (b). Specific DNA-repair pathways (c) remove the DNA lesion. Pathways shown in blue represent 'traditional' DNA repair, whereas pathways shown in green represent the bypassing of a DNA lesion, avoidance or reversal of DNA damage. Important components participating in the repair pathway in E. coli are shown in (d). Red lines indicate the cleaved DNA strand. All major DNA-repair pathways are present in Neisseria meningitidis (the meningococcus); however, the complexity of genes participating in each pathway are reduced in several cases (e). An understanding of meningococcal DNA-repair mechanisms, the interactions among these pathways and their contribution to the maintenance of genomic integrity deserves immediate attention. AP, abasic site; CPD, cyclobutane pyrimidine photodimer; EMS, ethanmethyl sulphonate; Me, methyl group; NER, nucleotide excision repair; $\mathrm{O}_{2}{ }^{--}$, superoxide radical; 8oxoG $\left(\mathrm{G}^{\circ}\right)$, 7,8-dihydro-8-oxo-2'-deoxyguanosine; P, pyrimidine; Sod, superoxide dismutase; SSB, single-stranded binding protein; TLS, translesion synthesis; UV, ultraviolet.

that defects in MMR might influence neisserial virulence, and showed that mutS mutants had a significantly increased frequency of phase variation and moderate increases in the rate of missense mutations ${ }^{22,23}$. However, most meningococcal mutators examined could not be complemented by mutS or mutL, indicating that other mechanisms also influence meningococcal mutability. This is supported by recent findings which show that meningococcal mutS mutants have lower spontaneous mutation rates compared with mutY mutants (FIG. 3). By contrast, in E. coli, defects in mutS induce higher mutation rates than defects in $m u t Y^{15}$ (FIG. 3).

Nucleotide excision repair and the SOS response. The NER pathway repairs bulky lesions caused by exogenous damage such as ultraviolet (UV) light or polycyclic aromatic hydrocarbons that interfere with normal base pairing, thereby impairing transcription and replication $^{24}$. In E. coli, NER is executed by the UvrABC complex, which removes a stretch of nucleotides that includes the lesion ${ }^{24,25}$ (FIG. 2). A gonococcal NER system that acts on pyrimidine dimers has been identified ${ }^{26}$, and the gonococcus expresses a $u v r A$ gene product that can restore UV resistance in an E. coli uvrA mutant ${ }^{27}$. The gonococcus also shows increased sensitivity to UV light on inactivation of the $u v r B$ gene $^{28}$, confirming a functional NER pathway. In contrast to $E$. coli NER genes, gonococcal $u v r A$ and $u v r B$ did not contain LexA-binding sites or SOS boxes, the general hallmarks of an active SOS response. In $E$. coli, the SOS response allows increased repair and the restoration of replication by inducing the expression of more than forty genes when there is a large amount of genomic DNA damage ${ }^{29,30}$. The lack of a functional gonococcal SOS response has been experimentally confirmed by Davies and co-workers who showed that exposure to the mutagen methyl methanesulphonate (MMS) and $U V$ radiation did not cause an increase in the gonococcal $u v r A$ and $u v r B$ transcripts ${ }^{31}$. The authors concluded that, in Neisseria, the prime effector of the SOS response, the RecA protein, has evolved for recombination purposes only. Although several homologues of genes known to be SOS-inducible are present in the neisseriae, neither SOS boxes nor a homologue of the gene encoding LexA have been identified ${ }^{9,10,32}$. 


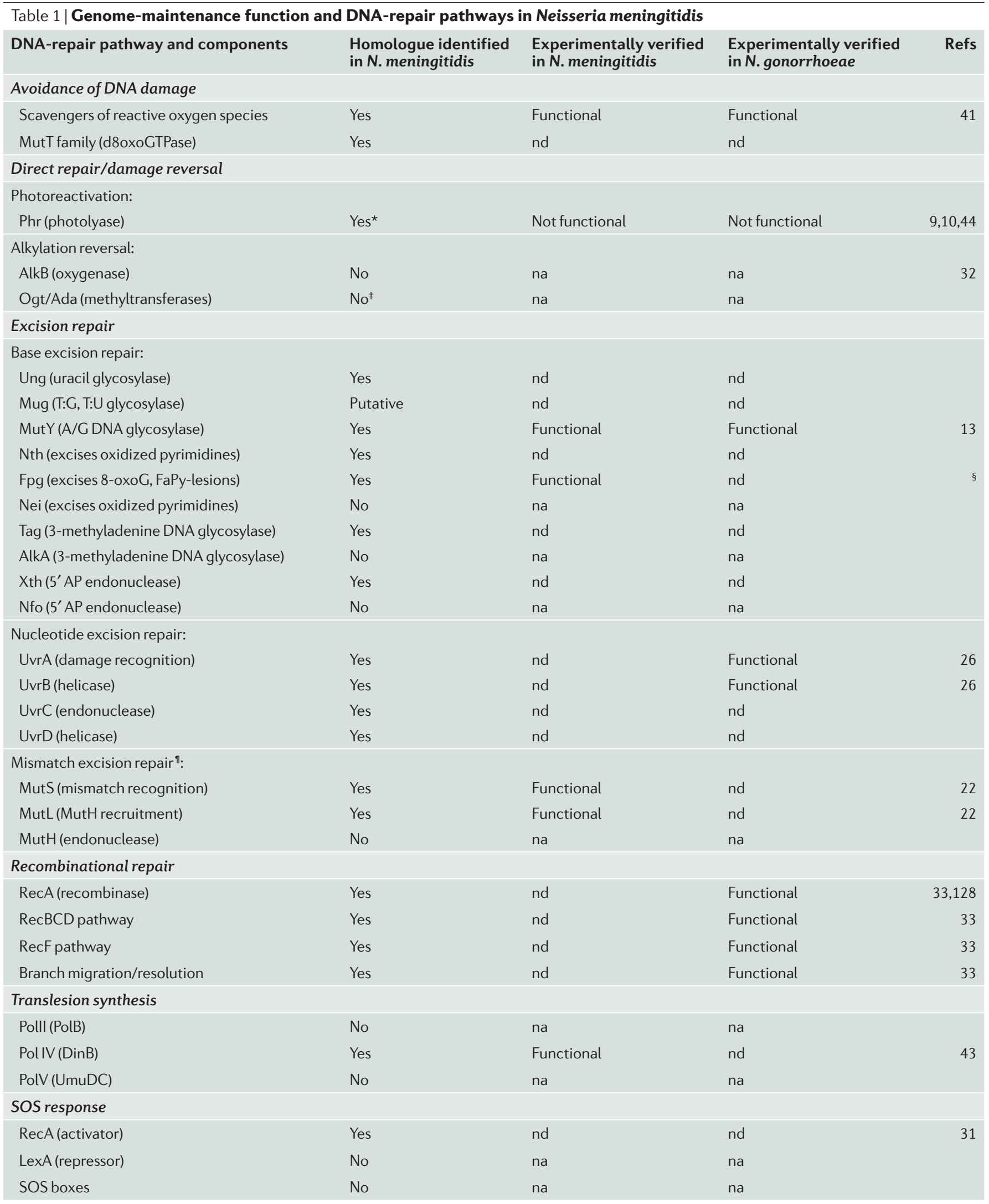

Results based on N. meningitidis MC58 and N. meningitidis Z2491 genome sequences, as well as experiments conducted in N. meningitidis and Neisseria gonorrhoeae (references cited). There are homologues to all known steps of the Escherichia coli base excision repair and nucleotide excision repair pathways. Absence of an SOS response has been experimentally confirmed in N. gonorrhoea $e^{31}$. *Authentic frameshift in N. meningitidis strain MC58 (REF. 10). *Partial sequence homology identified. The C-terminal part of NMB1528 (MC58)/NMA1728 (Z2491) protein (methylated-DNA-protein-cysteine methyltransferase) shows similarity to both E. coli Ada and Ogt. ${ }^{\$}$ T.D. and T.T., unpublished results. "Additional components usually associated with mismatch repair that are missing in one of the sequenced meningococcal genomes are vsr (identified in Z2491 but not MC58) and dam (identified in MC58 but not in Z2491). dcm is found in both Z2491and MC58. FaPy, formamidopyrimidine; na, not applicable; nd, not determined. 

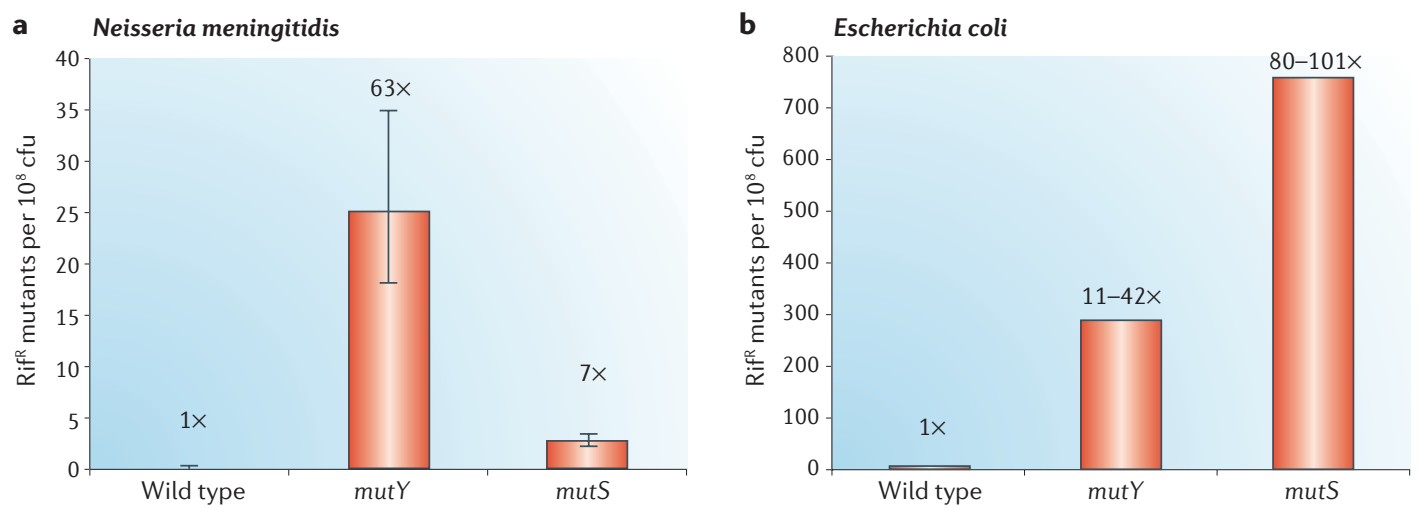

Figure 3 | Spontaneous mutagenicity of DNA-repair-deficient meningococci and Escherichia coli strains. The spontaneous mutation rates in mut $Y$ and mutS mutant meningococcus and $E$. coli strains compared with the wild type is shown. a | The spontaneous mutation rates of Neisseria meningitidis $\mathrm{H} 44 / 76$ wild-type and mut $\mathrm{Y}^{13}$ and mutS mutant strains as assessed by rifampicin acid resistance (Rif ${ }^{R}$ mutants). The results are the median of ten experiments for all strains investigated. The error bars represent \pm 1 quartile. Methods as referenced in REF. 13. b | The spontaneous mutation rates of E. coli wild-type and mutY and mutS mutant strains as assessed by rifampicin acid resistance ${ }^{15,123-126} \times$ is the fold increase of the mutant strains compared with the wild type. cfu, colony-forming units.

Recombinational repair. Owing to the absence of an SOS response, it is hypothesized that recombination pathways will be important for the pathogenic Neisseria as a response to double-strand breaks in DNA (FIG. 2). RecA has an important role in most meningococcal repeat-associated events, including those associated with homologous recombination, pilus antigenic variation and transformation ${ }^{33}$. Gonococcal RecA was first identified by complementation studies in E. coli ${ }^{34}$. Later, the function of E. coli RecA in the gonococcus was examined, and it was shown that species-specific interactions were important for RecA-dependent DNA-repair functions but not for homologous recombination $^{35}$. Several other rec genes also participate in neisserial recombinational pathways (reviewed in REF. 36). Although a $r e c F$ homologue is absent in the pathogenic Neisseria, the RecF-like and RecBCD-like pathways are present and involved in recombinational repair ${ }^{33}$, and gonococcal RecA functions in both pathways $^{33,34}$. Recombination during transformation also displayed partial requirement for RecBCD, RecN, RecX and a homologue of Rep, an E. coli ATP-dependent helicase $\mathrm{e}^{33,37,38}$. On the other hand, recombination associated with antigenic variation was supported by the RecF family members RecO, RecQ and RecJ, as well as $\operatorname{RecX}$ and $\operatorname{Rep}^{33,37-39}$. These components also take part in the recombinational repair pathway. Interestingly, meningococcal strains belonging to the hypervirulent lineage ET-37 have several missense mutations in the gene encoding $\operatorname{Rec} B$, which confers a UV-sensitive phenotype, increased mutagenicity after UV treatment and also increased pilin antigenic variation ${ }^{40}$. Defective DNA-repair alleles might therefore affect pathogenic traits by influencing the nature and the number of meningococcal variants created. However, RecB has been shown not to affect antigenic variation by Seifert and co-workers ${ }^{33}$, and the role of the RecBCD pathway in this process remains elusive.
Other DNA-repair strategies. In addition to the excision repair and recombinational pathways, the meningococcus has other strategies to avoid the mutagenic and cytotoxic effects of DNA damage. Compared with E. coli, the neisserial genomes have many more putative gene products that are involved in neutralizing DNA-damaging agents (TABLE 1), such as oxygen-radical scavengers like catalase and superoxide dismutase $(\text { SodC })^{41}$, which might reflect an adaptation to the burden of exogenous oxidative stress (FIG. 2). E. coli translesion synthesis (TLS) is undertaken by three DNA polymerases that allow replication past blocking lesions with the risk of inducing frameshifts (polII and polIV) or generating base substitutions (polV) ${ }^{42}$. The meningococcus, however, has only one translesion DNA polymerase (DinB), perhaps reflecting a reduced substrate spectrum for translesion synthesis. Also, the spontaneous mutation rate for a meningococcal strain that overexpresses DinB was not increased, as opposed to E. coli $i^{43}$. The consequences of the lack of RecA-controlled DNA-damage-inducible responses together with DinB activity can only be speculated upon. Assuming that the function of meningococcal DinB resembles its $E$. coli homologue in introducing frameshifts, this polymerase could be significant in the context of providing TLS past the many repeat regions in the meningococcal genome (see below).

In addition to the SOS response, the only mode of DNA repair that seems to be absent in the meningococcus is direct repair of DNA damage, or damage reversal. In 1979, Campbell showed that UV-irradiated gonococcal strains exposed to photoreactivating light showed no difference in survival compared with strains not subjected to photoreactivation ${ }^{44}$. Also, clinical meningococcal isolates exhibited the same trait, indicating that photolyase activity is not functional in the pathogenic Neisseria species $^{44}$, and that NER might be the main pathway dealing with neisserial UV-induced 


\begin{tabular}{|c|c|c|}
\hline & \multicolumn{2}{|l|}{ Number of genes } \\
\hline & $\begin{array}{l}\text { Escherichia coli } \\
\text { K12 }\end{array}$ & $\begin{array}{l}\text { Neisseria meningitidis } \\
\text { Z2491 }\end{array}$ \\
\hline \multicolumn{3}{|l|}{ Genetic adaptation } \\
\hline Phase and antigenic variation & $<10$ & $\sim 100$ \\
\hline \multicolumn{3}{|l|}{ Physiological adaptation } \\
\hline$\sigma$ factors & 7 & 3 \\
\hline Two-component regulatory systems & 662 & $<10$ \\
\hline Regulatory proteins (specific, global) & $\sim 110$ & $\sim 44$ \\
\hline Genome size $(\mathrm{Mb})$ & 4.6 & 2.2 \\
\hline Total number of genes & 4,288 & 2,065 \\
\hline
\end{tabular}

The number of genes was obtained from REF. 47 (E. coli K12) and REF. 9 (N. meningitidis).

\section{$\sigma$ factor}

A subunit of the RNA polymerase that dictates which promoters are being transcribed

Two-component regulatory systems

System that responds to an environmental stimulus and regulates gene expression accordingly. Composed of a histidine-kinase sensor, usually situated in the outer membrane, that phosphorylates a response regulator in the cytoplasm which in turn activates transcription from selected promoters.

Global regulatory component A component with a 'genomewide' regulatory function.

Regulatory response elements

Elements that respond to a change in the environment and subsequently regulate gene expression, for example, $\sigma$ factors, two-component regulatory systems and specific or global regulatory proteins.

Insertion sequences

A mobile stretch of DNA that can insertionally disrupt, and thereby inactivate, genes.
DNA-damage events. Genome sequencing confirmed an authentic frameshift in the deoxyribodopyrimidine photolyase $(p h r)$ gene, explaining the lack of this enzymatic property in the meningococcal strain MC58 (REF. 10). However, the meningococcal genomes Z2491 and FAM18, as well as the gonococcal genome FA1090, contain intact $p h r$ reading frames, and it has been suggested that the lack of photoreactivation is due to regulation by genes in a putative operon ${ }^{36}$. The lack of light in the neisserial habitat would also explain the reduced requirement for reversal of UV-induced damage by Phr. Intriguingly, all important alkylation-repair genes, except 3-methyladenine DNA glycosylase I (Tag), are absent in the meningococcus. In E. coli, the methyltransferases (Ada, Ogt) or iron-dependent dioxygenases (AlkB) remove the added methyl group. Alternatively, alkylated bases can be removed entirely by BER 3-methyladenine DNA glycosylases (Tag and AlkA) ${ }^{45}$. The lack of alkB and other alkylation-repair genes is a significant deviation, indicating that alkylation repair might not be in demand in the meningococcal habitat, that other repair pathways might exert this function or that Tag is sufficient for the repair of aberrant alkylated DNA.

In summary, homologues of $E$. coli genes encoding components of the major DNA-repair pathways BER, MMR, NER and recombinational repair are present in the meningococcus, although the complexity of genes participating in each pathway is reduced (TABLE 1). Only one homologue of $f p g / n e i$ (BER) and only a single gene encoding a DNA translesion polymerase are present ${ }^{36}$ (TABLE 1). By contrast, Mycobacterium tuberculosis genomes contain four homologues of $f p g / n e i^{46}$, whereas E. coli, as previously mentioned, harbours three different DNA translesion polymerases. The reduced repertoire of meningococcal genome-maintenance genes might reflect both genome-size economics and adaptations to the relatively protected habitat of the human oral mucosal surfaces.

Genome dynamics in the meningococcus and $E$. coli Meningococcal genomes possess several important characteristics that differ from those of E. coli. Not only do the genome sizes and number of genes differ, but genome dynamics are also disparate. E. coli shuttles between different environments, and therefore needs a battery of sophisticated regulatory systems to sense and respond to diverse environmental signals. For example, the E. coli genome has $7 \sigma$ factors and approximately 30 two-component regulatory systems ${ }^{47}$ (TABLE 2). These properties, in turn, necessitate a relatively large genome size and efficient DNA-repair systems to maintain this regulatory potential. The result is minimal genome variation, especially when compared with the meningococcus.

The meningococcus inhabits few sites within a single host, the human. This has allowed the evolution of a successful bacterial species with a relatively small genome and minimal regulatory networks. Meningococcal genomes contain only three $\sigma$ factors, five putative two-component regulatory systems, possibly with redundant functions, and only a few neisserial global regulatory components have been identified ${ }^{9}$ (TABLE 2). Also, certain repeats (the REP2 repeats) associated with genes that are coordinately regulated during host-cell adhesion ${ }^{48}$, and one recently identified inducible DNA-repair response that upregulates DNA-repair capacities and phase variation during colonization (see XseB below) ${ }^{49}$, are involved in responding to environmental changes. However, compared with $E$. coli, meningococci have few genes encoding regulatory response elements ${ }^{9,10}$. Along with a reduction in genome size, the meningococcal survival strategy involves a reduced DNA-repair capacity in combination with diverse systems that promote genome plasticity. Instead of sensing and responding to the environment, meningococcal cells generate a surplus of genetic variants that are subjected to natural selection ${ }^{50,51}$. Meningococcal adaptation is therefore dominated by random mutational events and not by regulated responses.

Mechanisms of meningococcal genome instability Meningococcal genome fluidity is promoted by spontaneous mutational mechanisms. These events originate either from local genomic changes caused by repeat sequences, phase and antigenic variation, recombination and horizontal gene transfer, or globally from mutator alleles. All contribute to the polyphyletic nature of meningococcal genomes. Phase and antigenic variation alone involve approximately 100 genes $^{9,10,52,53}$, whereas, in E. coli, less than 10 genes are subject to phase variation ${ }^{54}$ (TABLES 2,3).

Repeat sequence elements. The neisserial genomesequencing projects ${ }^{9,10}$ have revealed the presence of hundreds of repetitive DNA sequences with the associated intrinsic potential for genetic instability. These range from short repeats to insertion sequences and gene duplications of one $\mathrm{kb}$ or more. Repetitive DNA elements are important organizational components of the genome $e^{55}$. Repeats facilitate the duplication or deletion of regions of the genome, as well as recombination, and thereby establish small and large alterations that might be beneficial or detrimental. 
Natural transformation Binding and uptake of free DNA, which is subsequently integrated into the genome by recombination

\section{Correia elements} Small insertion elements of 100-150 bp that are flanked by long terminal repeats.

Neisserial intergenic mosaic elements

(NIMEs). Repeat units of 50-150 bp, each flanked by 20 -bp inverted repeats.

Homopolymeric tract Several identical copies of single, di- tri- or tetranucleotides.
The neisserial DNA uptake sequence. By far the most frequent repeat sequence element is the genus-specific neisserial DUS. This is a 10-bp sequence, $5^{\prime}$-GCCGTCTGAA-3', that is required for natural transformation of meningococci and gonococci ${ }^{56}$, and was first described by Goodman and Scocca in 1988 (REF. 57). Approximately 1,900 copies of the DUS are present in the genomes of both meningococci and gonococci $i^{9,10,56,58}$. Originally found as parts of inverted repeats downstream of genes, DUSs have been postulated to function as transcriptional regulators ${ }^{57}$. However, the complete genome sequences of meningococcal strains MC58 and Z2491 showed that DUSs are distributed throughout the genomes, both in intergenic and intragenic regions, and that many of them are present as single copies $^{9,10}$. When exposed to a mixture of homologous and foreign DNA, the neisseriae show preferential uptake of DUS-containing $\mathrm{DNA}^{59}$. It is not yet clear how the DUS functions in DNA binding and uptake and whether it has other functions, for instance in recombination. However, we have identified an overrepresentation of DUSs towards genes encoding DNA repair, recombination, replication and restriction/modification components ${ }^{58}$. A similar bias of the DNA uptake signal sequences (USS) (5'-AAGTGCGGT-3') towards genome-maintenance genes was found in genomes of the distantly related Pasteurellacea $^{58}$. These results imply that the high frequency of DUSs/USSs in genome-maintenance genes is conserved among phylogenetically divergent species and that these sequences are biologically important. The overrepresentation of DUSs and USSs in genomemaintenance genes might reflect facilitated recovery of genome-preserving functions. Uptake of such genes could provide a mechanism for enhanced recovery from DNA damage after genotoxic stress, ensuring their replacement through transformation if irreparably damaged or lost. The need for the DUS/USS pathway is evident by the fact that MMR genes such as mutS and mutL are frequently deteriorated by mutation and recombination events $^{60}$. Such deterioration creates mutators, but also generates a demand for gene restoration. Importantly, neisserial MMR genes have a particularly high DUS density, which facilitates their uptake ${ }^{58}$. Furthermore, the gene that encodes the DNA glycosylase MutY is the most DUS-dense of all neisserial DNA-repair genes ${ }^{58}$. It can be envisaged that a transient and beneficial increase in genome instability might be allowed during colonization and pathogenesis simply through inactivation or loss of antimutator genes. The overrepresentation of DUS in the crucial genome-maintenance genes might therefore reflect the benefits of maintaining or restoring the integrity of the repair machinery through preferential uptake of 'advantageous' DNA.

Coding tandem repeats. Coding tandem repeats are tandem repeats that do not disrupt the reading frame as they consist of repeat units composed of $3 \mathrm{bp}$ or multiples of $3 \mathrm{bp}$. Recently, Jordan and co-workers have shown that, in the meningococcus, there is repeatlength variation in genes not typically associated with phase variation, including the gene that encodes the transcription-repair coupling factor $\mathrm{Mfd}^{61}$. Also, the gene encoding the meningococcal outer-membrane secretin PilQ has 4-7 copies of a 24-nucleotide repeat, whereas gonococcal strains have only $2-3$ copies $^{62}$. Changes in the copy number of tandem repeats alter the structure and antigenicity of these components and might therefore represent an important, but largely unexplored, mechanism of generating meningococcal diversity.

Other neisserial repeat sequences. Other repeat sequences with incompletely determined functions such as Correia elements ${ }^{63-65}$, neisserial intergenic mosaic elements (NIMEs), large insertion elements, AT-rich repeats ${ }^{9}$ and REP2 repeats ${ }^{48}$ are also present in meningococcal genomes. These repeats are all suggested to have a role in genome organization, function and evolution ${ }^{66}$; however, more recently, Correia elements have been implicated in posttranscriptional regulation by cleavage of the transcript in the inverted repeat of the Correia element ${ }^{67}$. Also, many tandem repeats, ranging from homopolymeric tracts of $\mathrm{G}$ or $\mathrm{C}$ nucleotides to di-, tetra- and pentanucleotide repeats, have been identified, facilitating DNA-slippage events ${ }^{9,10,52}$.

Phase variation. Many bacteria have evolved mechanisms to produce high mutation rates in specific regions of their genomes, that is, localized hypermutation ${ }^{68}$. High mutation rates in specific loci result in the rapid generation of variants, which increases the diversity of a population. Among the elements causing localized hypermutation are short repeat sequences, for example, oligonucleotide repeats and microsatellites, which are widespread in bacteria such as Haemophilus and Neisseria ${ }^{68}$. When tandem repeats occur in the coding sequence, the promoter region or close to the promoter region, they can change the transcriptional and translational state of the gene, leading to an on/off switching of the gene product called phase variation (FIG 4). At the molecular level, phase variation is mediated by the addition and deletion of repeat units, most often owing to slipped-strand mispairing. Slipped-strand mispairing on the synthesis strand 
a

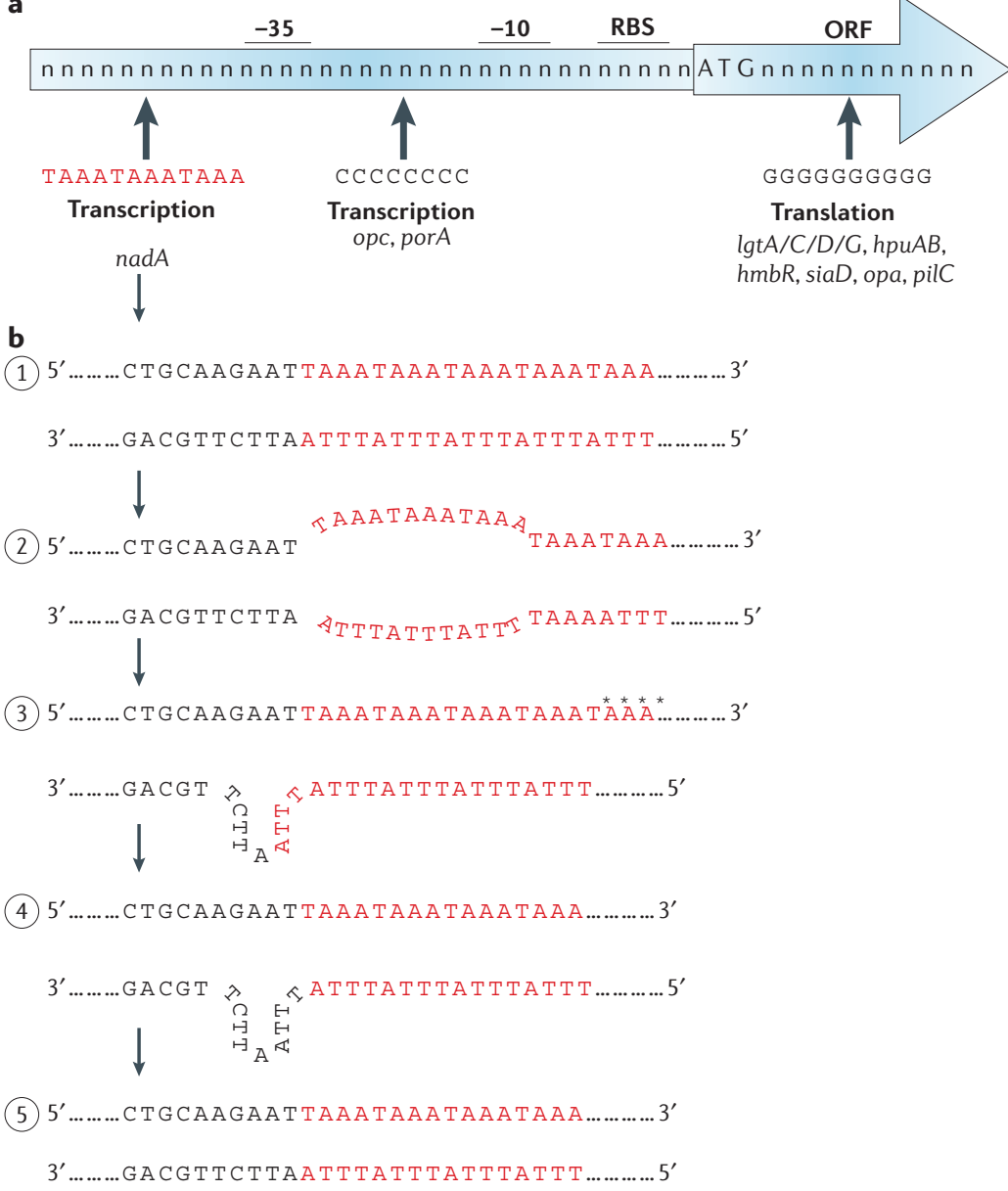

Figure 4 | Mechanisms of meningococcal phase variation. The molecular mechanism that most often mediates meningococcal phase variation is RecA-independent slippedstrand mispairing of repeats during DNA replication or repair. a | Tandem repeats are found either in the promoter region of the gene, affecting the binding of the RNA polymerase and therefore transcription, or in the open reading frame (ORF), affecting translation. These repeats can be homopolymeric or can be composed of tetranucleotides. The different meningococcal loci altered by phase variation and the corresponding position of tandem repeats are listed. $\mathbf{b} \mid$ The mutational mechanism responsible for phase variation of the meningococcal outer-membrane protein and adhesin NadA is shown. (1) When 5 TAAA repeats are present upstream of the promoter region, the expression level of NadA is high ${ }^{51}$. (2) The AT-rich sequence is prone to strand separation. (3) Subsequent mispairing of the TAAA repeats can occur during re-annealing due to slippage of the DNA strands. Slippage in the $5^{\prime}$ to $3^{\prime}$ direction as shown leaves an unpaired copy of TAAA (indicated by the asterisks). (4) The unpaired TAAA is deleted, and the single-stranded loop is the target of excision-repair processes. (5) With a reduction in the TAAA repeat number to four, the expression level of NadA is low ${ }^{51}$. Additionally, recombination by a mode of gene conversion (FIG. 5) can lead to phase variation when premature stop codons are removed or introduced into genes, resulting in functional or non-functional proteins, respectively. RBS, ribosomal binding site. Figure part $\mathbf{b}$ modified with permission from REF. 68 (C) (1994) Elsevier.

during replication and certain DNA-repair events generates addition events, whereas slipped-strand mispairing affecting the template strand induces deletion events. Phase variation can also occur by RecAdependent recombination through gene conversion when a stop codon is introduced or removed. More than 100

Gene conversion A non-reciprocal transfer of genetic information. putative phase-variable meningococcal genes have been identified in which phase variation is used to alter virulence-associated, surface-exposed molecules such as outer-membrane proteins PorA, Opc, opacity (opa) proteins, pili and specific adhesins, as well as lipo-oligosaccharide and capsule $e^{50,51,69-76}$ (TABLE 3). Genes that contain hypermutable sequences involved in phase variation have been termed 'contingency loci' by Moxon and co-workers as they allow the pathogen to spontaneously create genetic variants that might have a survival advantage when exposed to unpredictable events such as changing environmental conditions ${ }^{68}$. This mechanism provides the meningococcus with a large repertoire of phenotypes in a clonal population to escape the host immune system.

Recently, it has been shown that meningococcal strains associated with disease have high frequencies of phase variation, indicating a substantial benefit in varying surface components during transmission between hosts $^{22,23}$. The variation often stems from the lack of participation of MMR components - MMR mutS, mut $L$ and $u v r D$ defective strains show enhanced phase variation $^{22,23,43,77,78}$. There is conflicting evidence on the association between DNA adenine methyltransferase variants causing hypermutable neisserial strains with enhanced phase-variable capsule-switching ${ }^{79,80}$. So, the negative fitness impact associated with meningococcal DNA-repair defects might be balanced in vivo by an enhanced capability to create variants. Bacterial MMR-deficient mutants that show high mutation and homologous recombination rates are frequently found in natural populations. The sequence mosaicism of MMR genes might be a hallmark of a mechanism of adaptive evolution that involves modulation of mutation and recombination rates by recurrent losses and reacquisition of MMR gene functions ${ }^{60}$.

Recently, other DNA-repair pathways and metabolic components have been implicated in the control of phase variation. Overexpression of the single TLS DNA polymerase, DinB, increased the frequency of frameshifts in the short homopolymeric tract that controls the expression of meningococcal capsule (siaD), but had no effect on the frequency of frameshifts in long homopolymeric tracts. This indicates that, in the meningococcus, DinB does not mediate efficient proofreading on long homopolymeric tracts ${ }^{43}$. Also, PilP, the putative pilot protein of the secretin PilQ required for transformation, has been shown to increase the frequency of slippage events in mononucleotide repeat tracts, although the mechanism behind this increase remains unknown $^{78}$. Moreover, phase variation has been linked to transformation in other experiments: transforming DNA from various neisserial co-colonizers of the human nasopharynx was shown to increase meningococcal phase-variation frequencies, indicating that heterologous neisserial DNA modulates phase variation in a transformation-dependent manner ${ }^{77}$. However, the mechanism through which phase variation and transformation are related remains elusive. Interestingly, interplay between phase variation and classic global regulatory proteins, such as integration host factor, has also been identified in the meningococcus, adding to the complexity of the adaptive biology of this pathogen ${ }^{81}$. 


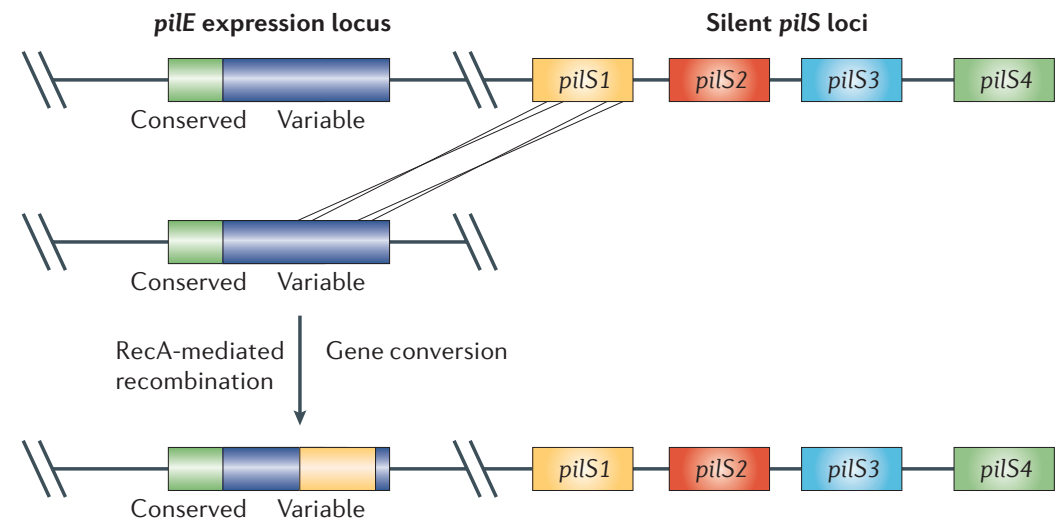

Figure 5 | Antigenic variation. Meningococcal pilin antigenic variation is mediated by gene conversion. Pili consist of thousands of pilin (PilE) subunits polymerized into long fibres. The PilE protein contains a highly conserved $\mathrm{N}$-terminal domain and a variable $\mathrm{C}$-terminal domain, the latter determining the antigenicity of the pili. The variable region is the result of a non-reciprocal transfer of DNA from one of many silent partial pilS loci to the single pilE expression locus. The silent loci, which are sometimes present several hundred bp away from the pilE expression locus, can donate a stretch of nucleotides, on the basis of short sequence homology. The genetic mechanism proceeds through a form of gene conversion that requires RecA and several crossover events during recombination.

Antigenic variation. Antigenic variation is a mechanism of immune evasion and refers to the expression of functionally conserved moieties that are antigenically distinct within a clonal population ${ }^{82}$. Only one variant is expressed at any given time, although the cell contains the genetic information to produce a whole range of antigenic variants. In the pathogenic Neisseria species, antigenic variation occurs in several surface components, including type IV pili, lipooligosaccharides and opa proteins ${ }^{83-89}$. The best characterized system is the expression of type IV pili, which involves RecA-dependent recombination similar to gene conversion ${ }^{84,88,90,91}$. The pilin subunit, PilE, consists of a highly conserved $\mathrm{N}$ terminus and a variable $\mathrm{C}$ terminus. The single pilE expression locus is changed by unidirectional donation of coding sequences from several silent partial pilS genes ${ }^{84,91-94}$ (FIG. 5).

Transformation. Transformation is the binding and uptake of exogenous DNA by a bacterial cell and the subsequent incorporation of this nascent DNA into the chromosome by homologous recombination ${ }^{95}$ (FIG. 6). Transformation is the predominant source of new genetic information integrated into the genome in the pathogenic Neisseria species ${ }^{96,97}$, and the relative contribution of transformation to horizontal gene transfer in nature has often been underrated. The pathogenic Neisseria species differ from other species in that they do not regulate competence like other naturally competent bacteria, such as Bacillus subtilis, Streptococcus pneumoniae and Haemophilus influenzae; instead, they are competent throughout their life cycle ${ }^{98-102}$. Efficient neisserial transformation is dependent on the presence of the 10-bp DUS in the exogenous DNA, type IV pilus expression and homologous recombination mediated by $\operatorname{Rec} \mathrm{A}^{34,59,103,104}$. Type IV pilus biogenesis requires a complex machinery to which the enigmatic processes involved in neisserial transformation are coupled ${ }^{105}$. A consistent theme in genetic transformation is the involvement of type IV pili or components related to the type IV pilus biogenesis machinery in the initial events of DNA recognition and uptake ${ }^{105}$. Recently, four proteins that are essential to DNA uptake were identified: PilQ (the secretin associated with pilus fibre extrusion), PilP (a lipoprotein required for PilQ complex stabilization), ComP (which shares structural identity with the type IV pilus fibre subunit protein) and PilT (required for pilus retraction and twitching motility ${ }^{62,106-108}$. Transformation of DNA between meningococcal and gonococcal strains occurs at a frequency of $10^{-1}-10^{-3}$ per cell. However, as shown by transformation studies, the pathogenic Neisseria species rarely take up DNA from bacterial species other than those in their own genus. One exception is the introduction of the gene that encodes $H$. influenzae SodC into the meningococcus by a horizontal-gene-transfer event $^{109}$.

Transforming DNA has traditionally been perceived as generating genetic variability and conferring change, such as antibiotic resistance ${ }^{110}$. However, our hypothesis is that transforming DNA also restores genes that are damaged after genotoxic stress, and therefore exerts a conserving function. Indirect evidence for this comes from findings that DUSs are overrepresented in DNA-repair and metabolism genes in phylogenetically different species, as discussed above $^{58}$. In this context, questions to be answered include the following: does DNA uptake function as a signal for repair/recombination? Is DNA uptake predominantly a source for genetic change or is it a mechanism for conservation and DNA repair? What are the contributions of recombination and transforming DNA to mutator activity?

Mutator alleles. Mutations in MMR genes usually result in a global increase in the rate of genetic variation, and generate a mutator phenotype. Mutators are beneficial in situations where there is an environmental flux or selective pressure, but any hypermutation also imposes a cost on the organism. Strains with an increased mutation rate form beneficial mutations more rapidly than strains with a low mutation rate, increasing the fitness of the population. However, bacteria with a prolonged high mutation rate have an increased accumulation of deleterious mutations, generating reduced fitness or non-viable genomes ${ }^{11}$. Hypermutable strains have been identified in E. coli ${ }^{112}$, Salmonella enterica serovar typhimurium ${ }^{113}$, Helicobacter pylori ${ }^{114}$, Pseudomonas aeruginos $a^{115}$ and $M$. tuberculosis ${ }^{116}$, indicating the presence of strong mutators when these bacteria inhabit certain environments. Mutators have been associated with increased survival rates ${ }^{117,118}$, overexpression of virulence factors ${ }^{119}$, outbreaks of epidemic disease ${ }^{23}$ and increased occurrence of antibiotic resistance ${ }^{115,116}$, but a general link between invasive disease and mutator phenotypes has not been clearly established. 


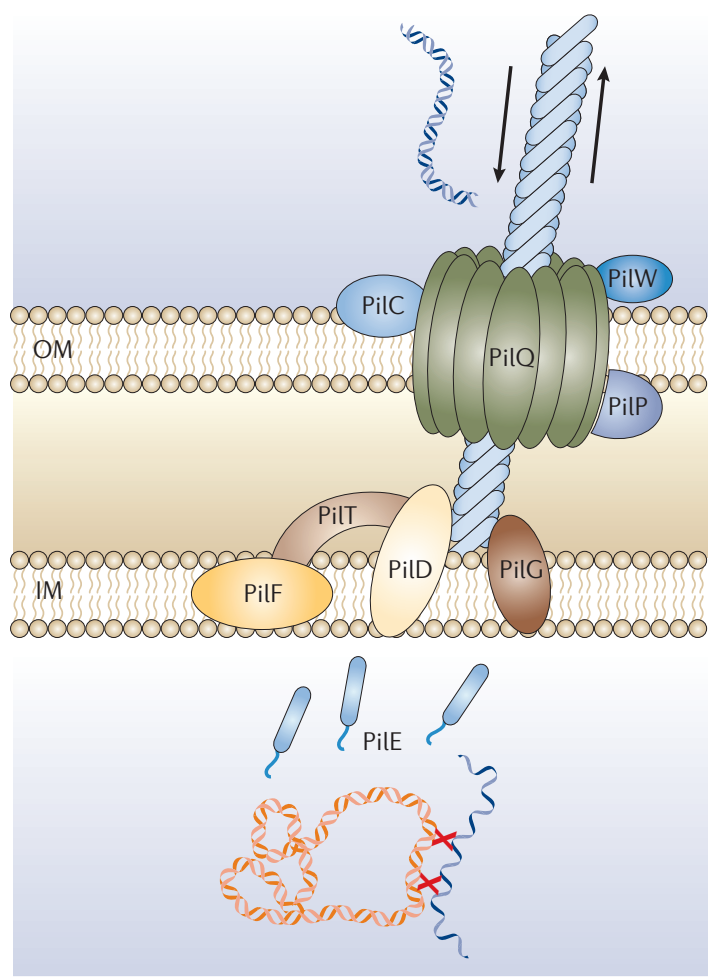

Figure 6 | Horizontal gene transfer by transformation of exogenous DNA. DNA in the environment can be entangled by retracting type IV pili and introduced into the cell through the outer (OM) and inner membranes (IM). Components of the type IV pilus biogenesis apparatus in Neisseria meningitidis are shown. In the cytoplasm, the incoming DNA (blue) is integrated into the genome (red) by homologous recombination ${ }^{127}$.

\section{Conclusions and perspectives}

The paradox of genome stability versus instability is most evident under stress when repair of lethal DNA lesions is absolutely required, but perfect restoration of original genetic information is not ${ }^{120}$. The meningococcus is continually exposed to stress in its oxygen-rich habitat as it competes with other microrganisms or suffers attacks from the human immune system. Studies that predict or modulate scenarios of adaptive mutations and evolution, both in experimental populations as well as in the natural host, have found that DNA-repair pathways have a crucial role in controlling such events ${ }^{121,122}$. Recently, meningococcal contact with host cells has been shown to induce a DNA-repair system; the upregulation of an open reading frame encoding a homologue to the $E$. coli exonuclease XseB enhanced meningococcal ability to repair DNA in vitro and increased the phase-variation frequency ${ }^{49}$. This finding emphasizes the importance of DNA-repair systems in the adaptation of the meningococcus to its niches during colonization of a new host ${ }^{49}$, implicating a pivotal role for DNA-repair pathways in the fitness and survival of this organism.

The balancing act between the ability to promote genetic variants and DNA-repair systems in the meningococcus raises several interesting questions: did the reduction in meningococcal genome size drive the degeneration of DNA-repair systems through convergent evolution, and did that in turn allow the proliferation of systems that promote genome variation? Alternatively, did the adoption of systems that promote the production of genetic variants create a cellular environment in which the retention of certain DNA-repair systems was a disadvantage? We do not as yet have answers to these, and other, important questions on meningococcal genome dynamics; we only have a few clues from the role of the natural transformation system, the overrepresentation of the DUS in DNArepair genes and the role of mutator strains.

Studies of these aspects of DNA metabolism in virulent microorganisms, and their relationships to genome (in)stability and strain variation, are in their infancy. The availability of DNA-sequence data for many microbial genomes has revealed marked evolutionary relatedness among genes involved in DNA repair and transformation, but also important differences. In retrospect, such differences would be expected because of the contrasts in physiology, lifestyles and environmental habitats between the various organisms. A comprehensive understanding of genome dynamics, including horizontal-gene-transfer mechanisms, recombination and DNA repair, requires a multidisciplinary approach. The combined experimental strategy should encompass systematic comparative genomics and bioinformatics searches, genetic screens and expression analyses with subsequent characterization of the three-dimensional structure and interactions, assessment of constructed mutants and relevant clinical isolates, and testing in animal models. Importantly, much can be learned by recognition of the structural and functional relationships between systems for genetic transformation, recombination and repair. However, many components specific for these processes remain to be identified, and we need a better understanding of the entire DNA-metabolism machinery in bacterial organisms. This new understanding is a prerequisite to combat the increasing occurrence of infectious diseases, and in this context the meningococcus is a most relevant model organism.
1. Anon. Meningococcal meningitis. World Health Organization [online], < http://www.who.int/ mediacentre/factsheets/fs 141/en/index.html > (2005).

2. Hardy, S. J., Christodoulides, M., Weller, R. O. \& Heckels, J. E. Interactions of Neisseria meningitidis with cells of the human meninges. Mol. Microbiol. 36 817-829 (2000)

3. Nassif, X. Microbiology. A furtive pathogen revealed. Science 287, 1767-1768 (2000).
4. Edwards, J. L. \& Apicella, M. A. The molecular mechanisms used by Neisseria gonorrhoeae to initiate infection differ between men and women. Clin. Microbiol. Rev. 17, 965-981 (2004).

5. Lindahl, T. Instability and decay of the primary structure of DNA. Nature 362, 709-715 (1993).

6. Eisen, J. A. \& Hanawalt, P. C. A phylogenomic study of DNA repair genes, proteins, and processes. Mutat Res. 435, 171-213 (1999).
Tonjum, T. \& Seeberg, E. Microbial fitness and genome dynamics. Trends Microbiol. 9, 356-358 (2001).

8. Hoeijmakers, J. H. Genome maintenance mechanisms for preventing cancer. Nature 411, 366-374 (2001).

9. Parkhill, J. et al. Complete DNA sequence of a serogroup A strain of Neisseria meningitidis Z2491. Nature 404, 502-506 (2000).

10. Tettelin, $\mathrm{H}$. et al. Complete genome sequence of Neisseria meningitidis serogroup B strain MC58. Science 287, 1809-1815 (2000). 
11. Demple, B. \& Harrison, L. Repair of oxidative damage to DNA: enzymology and biology. Annu. Rev. Biochem 63, 915-948 (1994)

12. Seeberg, E., Eide, L. \& Bjoras, M. The base excision repair pathway. Trends Biochem. Sci. 20, 391-397 (1995).

13. Davidsen, T., Bjoras, M., Seeberg, E. C. \& Tonjum, T. Antimutator role of DNA glycosylase MutY in pathogenic Neisseria species. J. Bacteriol. 187, 2801-2809 (2005).

The first complete characterization of a meningococcal DNA-repair protein, emphasizing the importance of BER in Neisseria species.

14. Nghiem, Y., Cabrera, M., Cupples, C. G. \& Miller, J. H. The mutY gene: a mutator locus in Escherichia coli that generates G.C $\rightarrow$ T.A transversions. Proc. Natl Acad. Sci. USA 85, 2709-2713 (1988).

15. Michaels, M. L., Cruz, C., Grollman, A. P. \& Miller, J. H. Evidence that MutY and MutM combine to prevent mutations by an oxidatively damaged form of guanine in DNA. Proc. Natl Acad. Sci. USA 89, 7022-7025 (1992).

16. Fowler, R. G. et al. Interactions among the Escherichia coli mutT, mutM, and mutY damage prevention pathways. DNA Repair (Amst.) 2, 159-173 (2003).

17. Schofield, M. J. \& Hsieh, P. DNA mismatch repair: molecular mechanisms and biological function. Annu. Rev. Microbiol. 57, 579-608 (2003)

18. Belland, R. J. H-DNA formation by the coding repeat elements of neisserial opa genes. Mol. Microbiol. 5, 2351-2360 (1991).

19. Lamers, M. H. et al. The crystal structure of DNA mismatch repair protein MutS binding to a $\mathrm{G} x \mathrm{~T}$ mismatch. Nature 407, 711-717 (2000).

20. Obmolova, G., Ban, C., Hsieh, P. \& Yang, W. Crystal structures of mismatch repair protein MutS and its complex with a substrate DNA. Nature 407, 703-710 (2000).

21. Ban, C., Junop, M. \& Yang, W. Transformation of MutL by ATP binding and hydrolysis: a switch in DNA mismatch repair. Cell 97, 85-97 (1999).

22. Richardson, A. R. \& Stojiljkovic, I. Mismatch repair and the regulation of phase variation in Neisseria meningitidis. Mol. Microbiol. 40, 645-655 (2001).

23. Richardson, A. R., Yu, Z., Popovic, T. \& Stojiljkovic, I. Mutator clones of Neisseria meningitidis in epidemic serogroup A disease. Proc. Natl Acad. Sci. USA 99, 6103-6107 (2002)

A high prevalence of mutators in serogroup A disease-associated isolates indicates that hypermutability might play a major role in meningococcal transmission between hosts.

24. Hanawalt, P. C. Subpathways of nucleotide excision repair and their regulation. Oncogene 21, 8949-8956 (2002).

25. Seeberg, E. Reconstitution of an Escherichia coli repair endonuclease activity from the separated $u v r A$ and $u v r B^{+} / 4 v r C^{+}$gene products. Proc. Natl Acad. Sci. USA 75, 2569-2573 (1978).

The first in vitro reconstitution of the NER pathway in $E$. coli using purified proteins.

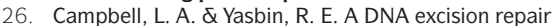 system for Neisseria gonorrhoeae. Mol. Gen. Genet. 193, 561-563 (1984)

27. Black, C. G., Fyfe, J. A. \& Davies, J. K. Cloning, nucleotide sequence and transcriptional analysis of the uvrA gene from Neisseria gonorrhoeae. Mol. Gen Genet. 254, 479-485 (1997).

28. Black, C. G., Fyfe, J. A. \& Davies, J. K. A promoter associated with the neisserial repeat can be used to transcribe the $u v r B$ gene from Neisseria gonorrhoeae. J. Bacteriol. 177, 1952-1958 (1995).

29. Courcelle, J., Khodursky, A., Peter, B., Brown, P. O. \& Hanawalt, P. C. Comparative gene expression profiles following UV exposure in wild-type and SOSdeficient Escherichia coli. Genetics 158, 41-64 (2001).

30. Freidberg, E. C., Walker, G. C. \& Siede, W. DNA Repair and Mutagenesis (ASM, Washington DC, 1995).

31. Black, C. G., Fyfe, J. A. \& Davies, J. K. Absence of an SOS-like system in Neisseria gonorrhoeae. Gene 208 61-66 (1998).

This paper describes an absence of an SOS response in $N$. gonorrhoeae and therefore highlights an important difference in the DNArepair profile of Neisseria and E. coli.

32. Falnes, P. O. \& Rognes, T. DNA repair by bacterial AlkB proteins. Res. Microbiol. 154, 531-538 (2003).
33. Mehr, I. J. \& Seifert, H. S. Differential roles of homologous recombination pathways in Neisseria gonorrhoeae pilin antigenic variation, DNA transformation and DNA repair. Mol. Microbiol. 30, 697-710 (1998).

34. Koomey, J. M. \& Falkow, S. Cloning of the $\operatorname{rec} A$ gene of Neisseria gonorrhoeae and construction of gonococcal recA mutants. J. Bacteriol. 169, 790-795 (1987).

35. Stohl, E. A., Blount, L. \& Seifert, H. S. Differential cross-complementation patterns of Escherichia coli and Neisseria gonorrhoeae RecA proteins. Microbiology 148, 1821-1831 (2002).

36. Kline, K. A., Sechman, E. V., Skaar, E. P. \& Seifert, H. S. Recombination, repair and replication in the pathogenic Neisseriae: the 3 R's of molecular genetics of two human-specific bacterial pathogens. $\mathrm{Mol}$. Microbiol. 50, 3-13 (2003).

37. Skaar, E. P., Lazio, M. P. \& Seifert, H. S. Roles of the recJ and recN genes in homologous recombination and DNA repair pathways of Neisseria gonorrhoeae. J. Bacteriol. 184, 919-927 (2002)

38. Kline, K. A. $\&$ Seifert, H. S. Role of the Rep helicase gene in homologous recombination in Neisseria gonorrhoeae. J. Bacteriol. 187, 2903-2907 (2005).

39. Hill S. A Neisseria gonorrhoeae recJ mutants show defects in recombinational repair of alkylated bases and UV-induced pyrimidine dimers. Mol. Gen. Genet. 264, 268-275 (2000)

40. Salvatore, P. et al. Phenotypes of a naturally defective $\mathrm{rec} B$ allele in Neisseria meningitidis clinical isolates. Infect. Immun. 70, 4185-4195 (2002).

41. Seib, K. L., Tseng, H. J., McEwan, A. G., Apicella, M. A $\&$ Jennings, M. P. Defenses against oxidative stress in Neisseria gonorrhoeae and Neisseria meningitidis: distinctive systems for different lifestyles. J. Infect. Dis. 190, 136-147 (2004)

42. Napolitano, R., Janel-Bintz, R., Wagner, J. \& Fuchs, R. P. All three SOS-inducible DNA polymerases (Pol II, Pol IV and Pol V) are involved in induced mutagenesis. EMBO J. 19, 6259-6265 (2000).

43. Martin, P., Sun, L., Hood, D. W. \& Moxon, E. R. Involvement of genes of genome maintenance in the regulation of phase variation frequencies in Neisseria meningitidis. Microbiology 150, 3001-3012 (2004).

44. Campbell, L. A. \& Yasbin, R. E. Deoxyribonucleic acid repair capacities of Neisseria gonorrhoeae: absence of photoreactivation. J. Bacteriol. 140, 1109-1111 (1979).

45. Sedgwick, B. \& Lindahl, T. Recent progress on the Ada response for inducible repair of DNA alkylation damage. Oncogene 21, 8886-8894 (2002).

46. Cole, S. T. et al. Deciphering the biology of Mycobacterium tuberculosis from the complete genome sequence. Nature 393, 537-544 (1998).

47. Blattner, F. R. et al. The complete genome sequence of Escherichia coli K-12. Science 277, 1453-1474 (1997)

48. Morelle, S., Carbonnelle, E. \& Nassif, X. The REP2 repeats of the genome of Neisseria meningitidis are associated with genes coordinately regulated during bacterial cell interaction. J. Bacteriol. 185 2618-2627 (2003)

49. Morelle, S., Carbonnelle, E., Matic, I. \& Nassif, X. Contact with host cells induces a DNA repair system in pathogenic Neisseriae. Mol. Microbiol. 55, 853-861 (2005).

50. Moxon, E. R., Lenski, R. E. \& Rainey, P. B. Adaptive evolution of highly mutable loci in pathogenic bacteria. Perspect. Biol. Med. 42, 154-155 (1998).

51. Feil, E. J. \& Spratt, B. G. Recombination and the population structures of bacterial pathogens. Annu. Rev. Microbiol. 55, 561-590 (2001).

52. Snyder, L. A., Butcher, S. A. \& Saunders, N. J. Comparative whole-genome analyses reveal over 100 putative phase-variable genes in the pathogenic Neisseria spp. Microbiology 147, 2321-2332 (2001)

Experimental verification of predicted meningococcal contingency genes, leading to identification of a novel phase-variable gene that contains a tetranucleotide repeat tract.

53. Martin, P. et al. Experimentally revised repertoire of putative contingency loci in Neisseria meningitidis strain MC58: evidence for a novel mechanism of phase variation. Mol. Microbiol. 50, 245-257 (2003).

54. Henderson, I. R., Owen, P. \& Nataro, J. P. Molecular switches - the ON and OFF of bacterial phase variation. Mol. Microbiol. 33, 919-932 (1999).

55. Shapiro, J. A. Repetitive DNA, genome system architecture and genome reorganization. Res. Microbiol. 153, 447-453 (2002).
56. Smith, H. O., Gwinn, M. L. \& Salzberg, S. L. DNA uptake signal sequences in naturally transformable bacteria. Res. Microbiol. 150, 603-616 (1999).

57. Goodman, S. D. \& Scocca, J. J. Identification and arrangement of the DNA sequence recognized in specific transformation of Neisseria gonorrhoeae. Proc. Natl Acad. Sci. USA 85, 6982-6986 (1988).

The identification of the nucleotide composition of the gonoccocal DUS required for transformation and its prevalence in putative transcriptional terminators.

58. Davidsen, T. et al. Biased distribution of DNA uptake sequences towards genome maintenance genes. Nucleic Acids Res. 32, 1050-1058 (2004). A higher density of DUSs in genes related to DNA repair, recombination, replication and restriction/ modification than in any other gene group was found in phylogenetically diverse neisserial and Pasteurellaceae species. This reflects facilitated recovery of genome-preserving functions after genotoxic stress

59. Elkins, C., Thomas, C. E., Seifert, H. S. \& Sparling, P. F Species-specific uptake of DNA by gonococci is mediated by a 10-base-pair sequence. J. Bacteriol. 173, 3911-3913 (1991).

60. Denamur, E. et al. Evolutionary implications of the frequent horizontal transfer of mismatch repair genes. Cell 103, 711-721 (2000)

61. Jordan, P., Snyder, L. A. \& Saunders, N. J. Diversity in coding tandem repeats in related Neisseria spp. BMC Microbiol. 3, 23 (2003).

62. Tonjum, T., Caugant, D. A., Dunham, S. A. \& Koomey, M. Structure and function of repetitive sequence elements associated with a highly polymorphic domain of the Neisseria meningitidis PilQ protein. Mol. Microbiol. 29, 111-124 (1998).

63. Correia, F. F., Inouye, S. \& Inouye, M. A family of smal repeated elements with some transposon-like properties in the genome of Neisseria gonorrhoeae. J. Biol. Chem. 263, 12194-12198 (1988)

64. Correia, F. F., Inouye, S. \& Inouye, M. A 26-base-pair repetitive sequence specific for Neisseria gonorrhoeae and Neisseria meningitidis genomic DNA. J. Bacteriol. 167, 1009-1015 (1986).

65. Mazzone, M. et al. Whole-genome organization and functional properties of miniature DNA insertion sequences conserved in pathogenic Neisseriae. Gene 278, 211-222 (2001)

66. Liu, S. V., Saunders, N. J., Jeffries, A. \& Rest, R. F. Genome analysis and strain comparison of correia repeats and correia repeat-enclosed elements in pathogenic Neisseria. J. Bacteriol. 184, 6163-6173 (2002).

67. Rouquette-Loughlin, C. E., Balthazar, J. T., Hill, S. A. \& Shafer, W. M. Modulation of the $m \operatorname{tr} C D E$-encoded efflux pump gene complex of Neisseria meningitidis due to a Correia element insertion sequence. Mol Microbiol. 54, 731-741 (2004).

68 Moxon, E. R., Rainey, P. B., Nowak, M. A. \& Lenski, R. E. Adaptive evolution of highly mutable loci in pathogenic bacteria. Curr. Biol. 4, 24-33 (1994).

The term 'contingency genes' was introduced to describe genes with high mutation rates that generate random phenotypic variation in Neisseria and $\boldsymbol{H}$. influenzae.

69. Murphy, G. L., Connell, T. D., Barritt, D. S., Koomey, M. $\&$ Cannon, J. G. Phase variation of gonococcal protein II: regulation of gene expression by slippedstrand mispairing of a repetitive DNA sequence. Cell 56, 539-547 (1989)

Identification of a RecA-independent slipped-strand mispairing mechanism of CTCTT repeats that regulates phase variation of gonococcal outermembrane protein II.

70. Kawula, T. H., Aho, E. L., Barritt, D. S., Klapper, D. G. $\&$ Cannon, J. G. Reversible phase variation of expression of Neisseria meningitidis class 5 outer membrane proteins and their relationship to gonococcal proteins II. Infect. Immun. 56, 380-386 (1988).

71. Sarkari, J., Pandit, N., Moxon, E. R. \& Achtman, M Variable expression of the Opc outer membrane protein in Neisseria meningitidis is caused by size variation of a promoter containing poly-cytidine. Mol. Microbiol. 13, 207-217 (1994).

72. Rudel, T. et al. Role of pili and the phase-variable PilC protein in natural competence for transformation of Neisseria gonorrhoeae. Proc. Natl Acad. Sci. USA 92 7986-7990 (1995). 
73. Hammerschmidt, S. et al. Capsule phase variation in Neisseria meningitidis serogroup B by slipped-strand mispairing in the polysialyltransferase gene $(\operatorname{sia})$ : correlation with bacterial invasion and the outbreak of meningococcal disease. Mol. Microbiol. 20. 1211-1220 (1996).

74. Rytkonen, A. et al. Neisseria meningitidis undergoes PilC phase variation and PilE sequence variation during invasive disease. J. Infect. Dis. 189, 402-409 (2004).

75. Jennings, M. P. et al. The genetic basis of the phase variation repertoire of lipopolysaccharide immunotypes in Neisseria meningitidis. Microbiology 145, 3013-3021 (1999).

76. Berrington, A. W. et al. Phase variation in meningococcal lipooligosaccharide biosynthesis genes. FEMS Immunol. Med. Microbiol. 34, 267-275 (2002).

77. Alexander, H. L., Richardson, A. R. \& Stojiljkovic, I. Natural transformation and phase variation modulation in Neisseria meningitidis. Mol. Microbiol. 52, 771-783 (2004).

78. Alexander, H. L., Rasmussen, A. W. \& Stojiljkovic, I. Identification of Neisseria meningitidis genetic loci involved in the modulation of phase variation frequencies. Infect. Immun. 72, 6743-6747 (2004).

79. Jolley, K. A., Sun, L., Moxon, E. R. \& Maiden, M. C. Dam inactivation in Neisseria meningitidis: prevalence among diverse hyperinvasive lineages. BMC Microbiol. 4, 34 (2004).

80. Bucci, C. et al. Hypermutation in pathogenic bacteria: frequent phase variation in meningococci is a phenotypic trait of a specialized mutator biotype. Mol Cell 3, 435-445 (1999).

81. Martin, P., Makepeace, K., Hill, S. A., Hood, D. W. \& Moxon, E. R. Microsatellite instability regulates transcription factor binding and gene expression. Proc. Natl Sci. USA 102, 3800-3804 (2005).

82. Borst, P. Molecular genetics of antigenic variation. Immunol. Today 12, A29-A33 (1991).

83 Connell, T. D., Shaffer, D. \& Cannon, J. C. Characterization of the repertoire of hypervariable regions in the Protein II (opa) gene family of Neisseria gonorrhoeae. Mol. Microbiol. 4, 439-449 (1990).

84. Swanson, J. et al. Gene conversion involving the pilin structural gene correlates with pilus + in equilibrium with pilus-changes in Neisseria gonorrhoeae. Cell 47, 267-276 (1986)

85. Bhat, K. S. et al. The opacity proteins of Neisseria gonorrhoeae strain MS11 are encoded by a family of 11 complete genes. Mol. Microbiol. 5, 1889-1901 (1991).

86. Aho, E. L., Dempsey, J. A., Hobbs, M. M Klapper, D. G. \& Cannon, J. G. Characterization of the opa (class 5) gene family of Neisseria meningitidis. Mol. Microbiol. 5, 1429-1437 (1991).

87. Vazquez, J. A. et al. Interspecies recombination in nature: a meningococcus that has acquired a gonococcal PIB porin. Mol. Microbiol. 15 , 1001-1007 (1995)

88. Hagblom, P., Segal, E., Billyard, E. \& So, M. Intragenic recombination leads to pilus antigenic variation in Neisseria gonorrhoeae. Nature 315, 156-158 (1985).

89. Stern, A., Brown, M., Nickel, P. \& Meyer T. F. Opacity genes in Neisseria gonorrhoeae: control of phase and antigenic variation. Cell 47, 61-71 (1986)

90. Koomey, M., Gotschlich, E. C., Robbins, K., Bergstrom, S. \& Swanson, J. Effects of recA mutations on pilus antigenic variation and phase transitions in Neisseria gonorrhoeae Genetics 117, 391-398 (1987).

91. Zhang, Q. Y., DeRyckere, D., Lauer, P. \& Koomey, M Gene conversion in Neisseria gonorrhoeae: evidence for its role in pilus antigenic variation. Proc. Natl Acad. Sci. USA 89, 5366-5370 (1992).

92. Gibbs, C. P. et al. Reassortment of pilin genes in Neisseria gonorrhoeae occurs by two distinct mechanisms. Nature 338, 651-652 (1989)

93. Perry, A. C., Nicolson, I. J. \& Saunders, J. R. Neisseria meningitidis $\mathrm{C} 114$ contains silent, truncated pilin genes that are homologous to Neisseria gonorrhoeae pil sequences. J. Bacteriol. 170, 1691-1697 (1988).

94. Swanson, J., Morrison, S., Barrera, O. \& Hill, S. Piliation changes in transformation-defective gonococci. J. Exp. Med. 171, 2131-2139 (1990). This paper and reference 91 show the role of gene conversion, and not transformation, in creating pilin variants.

95. Chen, I. \& Dubnau, D. DNA uptake during bacterial transformation. Nature Rev. Microbiol. 2, 241-249 (2004).
96. Koomey, M. Competence for natural transformation in Neisseria gonorrhoeae: a model system for studies of horizontal gene transfer. APMIS Suppl. 84, 56-61 (1998)

97. Fussenegger, M., Rudel, T., Barten, R., Ryll, R. \& Meyer, T. F. Transformation competence and type- 4 pilus biogenesis in Neisseria gonorrhoeae - a review. Gene 192, 125-134 (1997).

98. Jyssum, K. \& Lie, S. Genetic factors determining competence in transformation of Neisseria meningitidis. 1. A permanent loss of competence. Acta Pathol. Microbiol. Scand. 63, 306-316 (1965). The first demonstration of natural competence for transformation in $N$. meningitidis.

99. Sparling, P. F. Genetic transformation of Neisseria gonorrhoeae to streptomycin resistance. J. Bacteriol. 92, 1364-1371 (1966).

100. Singh, R. N. \& Pitale, M. P. Competence and deoxyribonucleic acid uptake in Bacillus subtilis. J. Bacteriol. 95, 864-866 (1968).

101. Havarstein, L. S., Coomaraswamy, G. \& Morrison, D. A An unmodified heptadecapeptide pheromone induces competence for genetic transformation in Streptococcus pneumoniae. Proc. Natl Acad. Sci. USA 92, 11140-11144 (1995).

102. MacFadyen, L. P. et al. Competence development by Haemophilus influenzae is regulated by the availability of nucleic acid precursors. Mol. Microbiol. 40 700-707 (2001).

103. Graves, J. F., Biswas, G. D. \& Sparling, P. F. Sequence-specific DNA uptake in transformation of Neisseria gonorrhoeae. J. Bacteriol. 152, 1071-1077 (1982).

104. Biswas, G. D., Sox, T., Blackman, E. \& Sparling, P. F. Factors affecting genetic transformation of Neisseria gonorrhoeae. J. Bacteriol. 129, 983-992 (1977).

105. Tonjum, T. \& Koomey, M. The pilus colonization factor of pathogenic neisserial species: organelle biogenesis and structure/function relationships - a review. Gene 192, 155-163 (1997).

106. Collins, R. F. et al. Interaction with type IV pili induces structural changes in the bacterial outer membrane secretin PilQ. J. Biol. Chem. 280, 18923-18930 (2005).

107. Wolfgang, M., van Putten, J. P., Hayes, S. F. \& Koomey, M. The comP locus of Neisseria gonorrhoeae encodes a type IV prepilin that is dispensable for pilus biogenesis but essential for natural transformation. Mol. Microbiol. 31, 1345-1357 (1999).

108. Aas, F. E., Lovold, C. \& Koomey, M. An inhibitor of DNA binding and uptake events dictates the proficiency of genetic transformation in Neisseria gonorrhoeae: mechanism of action and links to Type IV pilus expression. Mol. Microbiol. 46, 1441-1450 (2002).

109. Kroll, J. S., Wilks, K. E., Farrant, J. L. \& Langford, P. R. Natural genetic exchange between Haemophilus and Neisseria: intergeneric transfer of chromosomal genes between major human pathogens. Proc. Natl Acad. Sci. USA 95, 12381-12385 (1998).

110. Spratt, B. G., Bowler, L. D., Zhang, Q. Y., Zhou, J. \& Smith, J. M. Role of interspecies transfer of chromosomal genes in the evolution of penicillin resistance in pathogenic and commensal Neisseria species. J. Mol. Evol. 34, 115-125 (1992). Highlights the importance of DNA transformation in the spread of antibiotic resistance from commensal to pathogenic Neisseria.

111. Sniegowski, P. D., Gerrish, P. J. \& Lenski, R. E. Evolution of high mutation rates in experimental populations of E. coli. Nature 387, 703-705 (1997)

112. Matic, I. et al. Highly variable mutation rates in commensal and pathogenic Escherichia coli. Science 277, 1833-1834 (1997).

113. LeClerc, J. E., Li, B., Payne, W. L. \& Cebula, T. A. High mutation frequencies among Escherichia coli and Salmonella pathogens. Science 274, 1208-1211 (1996).

114. Bjorkholm, B. et al. Mutation frequency and biological cost of antibiotic resistance in Helicobacter pylori. Proc. Natl Acad. Sci. USA 98, 14607-14612 (2001)

115. Oliver, A., Canton, R., Campo, P., Baquero, F. \& Blazquez, J. High frequency of hypermutable Pseudomonas aeruginosa in cystic fibrosis lung infection. Science 288, 1251-1254 (2000). The identification of a high proportion of mutators in $P$. aeruginosa isolates from cystic fibrosis patients indicates a link between high mutation rates in vivo and the evolution of antibiotic resistance.
116. Rad, M. E. et al. Mutations in putative mutator genes of Mycobacterium tuberculosis strains of the WBeijing family. Emerg. Infect. Dis. 9, 838-845 (2003)

117. Giraud, A. et al. Costs and benefits of high mutation rates: adaptive evolution of bacteria in the mouse gut Science 291, 2606-2608 (2001).

118. Notley-McRobb, L., Seeto, S. \& Ferenci, T. Enrichment and elimination of mutY mutators in Escherichia coli populations. Genetics 162, 1055-1062 (2002).

119. Harris, S. L. et al. Isolation and characterization of mutants with lesions affecting pellicle formation and erythrocyte agglutination by type 1 piliated Escherichia coli. J. Bacteriol. 172, 6411-6418 (1990)

120. Matic, I., Taddei, F. \& Radman, M. Survival versus maintenance of genetic stability: a conflict of priorities during stress. Res. Microbiol. 155, 337-341 (2004).

121. Rosenberg, S. M. \& Hastings, P. J. Microbiology and evolution. Modulating mutation rates in the wild. Science 300, 1382-1383 (2003).

122. Wright, B. E. Stress-directed adaptive mutations and evolution. Mol. Microbiol. 52, 643-650 (2004)

123. Blaisdell, J. O., Hatahet, Z. \& Wallace, S. S. A novel role for Escherichia coli endonuclease VIII in prevention of spontaneous $\mathrm{G} \rightarrow \mathrm{T}$ transversions. J. Bacteriol. 181, 6396-6402 (1999).

124. Lu, A. L. \& Fawcett, W. P. Characterization of the recombinant MutY homolog, an adenine DNA glycosylase, from yeast Schizosaccharomyces pombe. J. Biol. Chem. 273, 25098-25105 (1998).

125 Prudhomme, M., Mejean, V., Martin, B. \& Claverys, J. P. Mismatch repair genes of Streptococcus pneumoniae: HexA confers a mutator phenotype in Escherichia coli by negative complementation. J. Bacteriol. 173, 7196-7203 (1991).

126. Biswas, I. et al. Disruption of the helix-u-turn-helix motif of MutS protein: loss of subunit dimerization, mismatch binding and ATP hydrolysis. J. Mol. Biol. 305, 805-816 (2001).

127. Tonjum, T., Havarstein, L. S., Koomey, M. \& Seeberg, E. Transformation and DNA repair: linkage by DNA recombination. Trends Microbiol. 12, 1-4 (2004)

128. Segal, E., Hagblom, P., Seifert, H. S. \& So, M Antigenic variation of gonococcal pilus involves assembly of separated silent gene segments Proc. Natl Acad. Sci. USA 83, 2177-2181 (1986).

129. Jonsson, A. B., Nyberg, G. \& Normark, S. Phase variation of gonococcal pili by frameshift mutation in pilC, a novel gene for pilus assembly. EMBO J. 10 477-488 (1991).

130. Stern, A. \& Meyer, T. F. Common mechanism controlling phase and antigenic variation in pathogenic Neisseriae. Mol. Microbiol. 1, 5-12 (1987).

131. van der Ende, A. et al. Variable expression of class 1 outer membrane protein in Neisseria meningitidis is caused by variation in the spacing between the -10 and -35 regions of the promoter. J. Bacteriol. 177 , 2475-2480 (1995).

132. Lewis, L. A. et al. Phase variation of HpuAB and $\mathrm{HmbR}$, two distinct haemoglobin receptors of Neisseria meningitidis DNM2. Mol. Microbiol. 32, 977-989 (1999)

Acknowledgments

We deeply appreciate the discussions with the late Erling Seeberg on mechanisms of DNA repair. We thank O.H. Ambur and I. Alseth for critical reading of the manuscript.

Competing interests statement

The authors declare no competing financial interests.

\section{DATABASES}

The following terms in this article are linked online to: Entrez: http://www.ncbi.nlm.nih.gov/Entrez Bacillus subtilis | Escherichia coli | Haemophilus influenzae | Helicobacter pylori|Mycobacterium tuberculosis|Neisseria gonorrhoeae | Neisseria meningitidis | Pseudomonas aeruginosa | Salmonella enterica serovar typhimurium |Streptococcus pneumoniae

\section{FURTHER INFORMATION}

Tone Tønjum's research homepages:

http://www.cmbn.no/group-tonjum.html

http://www.cmbn.no/tonjum

Neisseria gonorrhoeae strain FA 1090 genome: http://www.genome.ou.edu/gono.html Neisseria meningitidis serogroup $\mathrm{C}$ strain FAM18 genome: http://www.sanger.ac.uk/Projects/N_meningitidis/seroC/ seroC.shtml

Access to this interactive links box is free online. 